\title{
Análise Simplificada de Uma Argamassa de Cal
}

\author{
João Pires \\ Centro de Química e Bioquímica, Faculdade de Ciências, Universidade de Lisboa \\ jpsilva@ciencias.ulisboa.pt
}

\begin{abstract}
Simple Analysis of Historical Lime Mortars - This laboratory experiment describes a simple characterization of an historical lime mortar by the determination of its approximate composition by a gravimetric method. FTIR spectroscopy and X-ray diffraction are also used for the qualitative characterization of the mortar components. These types of experiments are particularly suitable to teach aspects of general chemistry, and to present techniques such as FTIR or X-ray diffraction, at an introductory laboratory level to students that have their major in courses that are related with the cultural heritage, but also have science disciplines, such as Chemistry.
\end{abstract}

\begin{abstract}
Descreve-se uma experiência laboratorial na qual é empregue um método gravimétrico para a determinação da composição aproximada de uma argamassa de cal. A espectroscopia de infravermelho e a difracção de raios-X são também utilizadas para a análise qualitativa dos constituintes principais da argamassa. Este tipo de experiências são particularmente adequadas para o ensino de vários aspectos de química geral bem como para apresentar a espectroscopia de infravermelho e a difracção de raios- $X$ a um nível laboratorial introdutório a alunos que, embora tendo a parte principal das disciplinas do seu curso noutras áreas de estudo, como por exemplo áreas relacionadas com as artes e o património, frequentam também disciplinas de áreas científicas como a Química.
\end{abstract}

\section{INTRODUÇÃO}

O interesse dos alunos por cursos da área das ciências tem vindo a declinar nos últimos anos, facto que é conhecido e que também é matéria de debate em vários países [1-3]. De entre estas áreas científicas a química tem sido particularmente atingida. As causas para esta situação são múltiplas e complexas [3] e as soluções não são fáceis de encontrar. Todas as contribuições para que haja uma percepção mais correcta da química por um conjunto o mais amplo possível de cidadãos são relevantes neste contexto. Uma via para isto, ainda que não tenha sido obviamente inventada agora, é a relação entre a química e as ciências ligadas à conservação ou, num âmbito mais geral, à temática do património cultural. Esta relação pode ser feita, por exemplo, através de aplicações instrumentais [4] ou através de cursos em que escolas de ciências e escolas de artes colaboram. Este último aspecto permite o ensino da química a nível universitário mas a estudantes que têm um nível de conhecimentos de química pré-universitário por vezes reduzido. Assim, e porque a química é uma ciência experimental, a selecção de experiências relativamente simples mas motivantes para ensinar questões básicas de química é particularmente importante neste contexto.

Existem na literatura várias propostas e descrições de experiências laboratoriais que têm relação com as artes e com o património cultural mas, a maioria, relaciona-se com corantes e pigmentos [5]. Curiosamente, poucas referências têm sido feitas, neste contexto, a experiências laboratoriais com argamassas históricas, nomeadamente argamassas de cal. A principal razão para este facto é, muito provavelmente, porque amostras de argamassas históricas para estudar poderão não ser muito acessíveis. Porém, esta limitação também é uma oportunidade para que uma escola ou departamento de química possa interagir com a comunidade que os rodeia e, assim, contribuir para uma melhor percepção da química fora do meio universitário. Dependendo da situação específica, vários procedimentos podem ser adoptados, por exemplo, protocolos para o estudo de amostras podem ser feitos com museus ou outras instituições ligadas à conservação. A análise de argamassas históricas é uma temática interessante uma vez que a sua composição, entre outros aspectos que podem ser estudados, pode fornecer informação com propósitos de estudos arqueológicos e de conservação [6]. Uma lista de publicações em que a análise de argamassas históricas foi realizada com objectivos arqueológicos ou de conservação está reunida na Informação de Suporte. No presente texto descreve-se um exemplo de uma análise simplificada de uma argamassa de cal com o objectivo principal de poder ser realizada por estudantes com relativamente poucos conhecimentos pré-universitários de química. Algumas potencialidades de expandir esta actividade laboratorial são também discutidas.

\section{DESCRIÇÃO GLOBAL DA EXPERIÊNCIA}

As argamassas de cal são constituídas por três constituintes principais. Dois deles são as fracções que estão presentes em maior quantidade: o ligante (essencialmente carbonato de cálcio) e os agregados (ou areias) que são essencialmente sílica. O terceiro componente existe em pequena quantidade, podendo denominar-se por "finos" e é composto por exemplo por minerais de argila. Vários procedimentos experimentais têm sido propostos para a análise de argamassas de cal [7] e a comparação de resultados obtidos utilizando diferentes procedimentos foi também já discutida na literatura [8] mas o método mais comum envolve o ataque 
ácido da argamassa com ácido clorídrico para provocar a dissolução do ligante, permitindo determinar a percentagem mássica de ligante na argamassa total, bem como a percentagem mássica de agregados e de “finos”.

As técnicas experimentais a utilizar são simples mas importantes em química (pesagem rigorosa, decantação, filtração, preparação de soluções) e podem ser efectuadas por estudantes de cursos com pouca prática de química laboratorial. Numa fase mais avançada dos cursos, ou em estreita relação com disciplinas mais focadas na instrumentação, as argamassas históricas podem voltar a ser utilizadas como objecto de estudo. Por exemplo, aplicações relacionadas com a espectroscopia de infravermelho com transformada de Fourier (FTIR) ou a difracção de raios-X (DRX) podem ser exemplificadas através da identificação das bandas de infravermelho ou dos picos de difracção do ligante e dos agregados $[7,8]$.

\section{Procedimentos eXPeRIMENTAIS}

\section{AnÁlise Química}

São necessários cerca de $25 \mathrm{~cm}^{3}$ de uma solução de $\mathrm{HCl}$ 3 ou 4 M por análise. Dependendo dos objectivos do curso, e do grau de preparação anterior dos alunos, esta solução pode já estar preparada ou pode ser dada aos alunos a oportunidade de a preparar a partir de uma solução de $\mathrm{HCl}$ concentrado, ilustrando as precauções necessárias para o efeito. A concentração da solução não é absolutamente crítica pelo que uma diluição de um volume de $\mathrm{HCl}$ concentrado (usualmente 37\%) em 3 volumes de água destilada é suficiente.

Previamente à análise, os estudantes efectuam uma observação cuidadosa das características da amostra de argamassa, tomando nota da cor, forma, grau de homogeneidade, etc. Nesta fase, é importante sensibilizar os alunos para a importância de uma correcta amostragem. No caso de a amostra não estar desagregada pode necessitar de ser partida (eventualmente com um martelo) e seguidamente moída num almofariz por forma a obter um pó mais finamente dividido. Uma vez desagregada, a amostra deverá ser colocada numa estufa a $100{ }^{\circ} \mathrm{C}$ e posteriormente arrefecida em exsicador. Cerca de $1 \mathrm{~g}$ de amostra é então rigorosamente pesado (w1) num copo de $25 \mathrm{~cm}^{3}$ cuja massa foi também registada (w2). Adicionam-se $3 \mathrm{~cm}^{3}$ de água destilada ao copo e coloca-se num agitador magnético com uma barra de agitação. Enquanto a agitação prossegue, adiciona-se o HCl preparado, gota a gota, até que a efervescência termine.

Neste ponto, o ligante $\left(\mathrm{CaCO}_{3}\right)$ reagiu com o $\mathrm{HCl}$, tendo-se libertado $\mathrm{CO}_{2}$, permanecendo em solução os iões cálcio. Assim, a fase sólida é agora composta pelos agregados e pela fracção de "finos”. O objectivo neste ponto é efectuar uma decantação para que os agregados (partículas maiores) permaneçam no copo mas os "finos” sejam transferidos com a fase líquida, sendo separados por filtração. Para o efeito, começa por se remover o agitador magnético e pesa-se uma folha de papel de filtro (w3) colocando-a num funil. Agita-se a mistura que está no copo com uma vareta de vidro e decanta-se, vertendo o líquido para o papel de filtro. Este passo é repetido várias vezes, adicionando pequenas quantidades de água em cada passo. Como as dimensões dos agregados e dos finos são muito diferentes, este tipo de decantação/filtração permite a sua separação. Depois de seco, o papel de filtro é pesado (w4) bem como o copo com os agregados (w5). A composição percentual abreviada da argamassa pode ser calculada conforme indicado na Tabela 1.

Tabela 1 - Cálculo dos constituintes principais da argamassa

\begin{tabular}{|l|r|}
\hline \% de agregados & $((w 5-w 2) / w 1) \times 100$ \\
\hline$\%$ de finos & $((w 4-w 3) / w 1) \times 100$ \\
\hline$\%$ de ligante & $100-\%$ de agregados - \% de finos \\
\hline
\end{tabular}

Extensão do Trabalho Experimental: CaracterizaÇÃo por FTIR E DRX

Para a obtenção dos espectros de infravermelho, o método da pastilha, por diluição em $\mathrm{KBr}$, é preferível (exemplo na Figura 1). O difractograma de raios-X pode ser obtido pelo método dos pós (exemplo na Figura 2). Em ambas as análises, de FTIR e de DRX, podem surgir algumas dificuldades relacionadas com a heterogeneidade de algumas amostras, em particular pode observar-se heterogeneidade nas dimensões das partículas dos agregados. Assim, pode ser requerida uma moagem adicional antes de efectuar as pastilhas para o FTIR. Adicionalmente, no caso das partículas dos agregados serem demasiado grandes, mesmo para análise por DRX pode ser aconselhável efectuar pastilhas, de uma forma semelhante ao que se faz para o FTIR mas sem diluir com $\mathrm{KBr}$.

\section{RESULTADOS E DISCUSSÃO}

Os estudantes deverão começar por interpretar, do ponto de vista químico, o que sucede na parte experimental, nomeadamente escrevendo o esquema químico que traduz a reacção entre o $\mathrm{HCl}$ e o $\mathrm{CaCO}_{3}$. Com os valores das massas, w1 a w5, e conforme a Tabela 1, a composição percentual da argamassa pode ser calculada. Dependendo do número de estudantes (ou grupos) e da quantidade de amostra disponível, as análises poderão ser replicadas. Em qualquer caso, a comparação de resultados entre os vários alunos ou grupos de alunos é importante. Com efeito, pode antecipar-se alguma variação nas composições determinadas dada a possível heterogeneidade das amostras. Este aspecto deve ser enfatizado na discussão dos resultados uma vez que ajuda a ilustrar a importância do passo de amostragem.

A Figura 1 exemplifica um espectro FTIR de uma argamassa de cal. É instrutivo obterem-se os espectros de uma sílica (ex. quartzo) e do carbonato de cálcio puros, os quais são os constituintes principais da argamassa para que se possa efectuar uma comparação das principais bandas de absorção dos componentes puros e da amostra de argamassa. No caso do carbonato de cálcio as bandas próximo de 


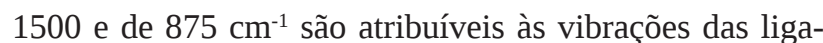
ções O-C-O do grupo carbonato. As bandas mais intensas da sílica surgem a cerca de 1080 and $780 \mathrm{~cm}^{-1}$. Conforme esperado, as bandas mais intensas da sílica e do carbonato de cálcio também aparecem no espectro FTIR da amostra de argamassa.

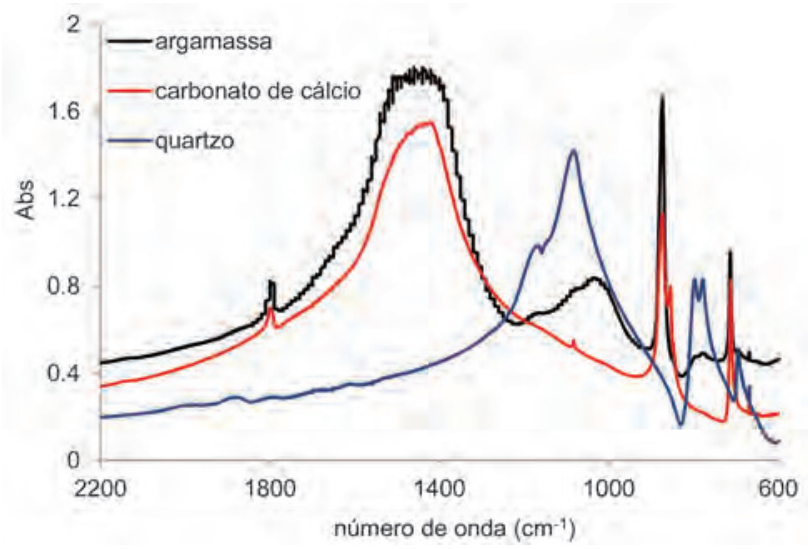

Figura 1 - Espectro FTIR de uma argamassa de cal, e de amostras de quartzo e de carbonato de cálcio. Adaptado com permissão de J. Chem. Educ. 2015, 92, 521-523. (Copyright 2015 American Chemical Society)

A Figura 2 ilustra um exemplo de um difractograma de raios-X de uma argamassa de cal em que os picos correspondentes aos constituintes principais da amostra foram atribuídos de acordo com os respectivos ficheiros ICDD (International Center for Diffraction Data). Uma listagem sumária dos picos de difracção para alguns componentes relevantes de argamassas históricas está presentada na Informação de Suporte.

Conforme se pode verificar, a Figura 2 apresenta os picos relativos ao quartzo e à calcite, bem como picos relativos a outros componentes minoritários como minerais de argila (muscovite) e feldspatos.

\section{CONCLUSÕES}

As experiências descritas ilustram os aspectos principais de uma caracterização abreviada de uma amostra de argamassa histórica. Trata-se de um trabalho adequado para ensinar um conjunto de assuntos de química a estudantes que frequentam cursos em que o maior número de disciplinas está centrado em assuntos relacionados com as artes e o património mas que também têm uma componente de disciplinas de química, uma vez que as experiências propostas permitem relacionar as diferentes vertentes dos seus cursos.

\section{INFORMAÇÃO DE SUPORTE}

Procedimentos experimentais detalhados; folha de registo para a análise química; resumo dos picos de difracção de

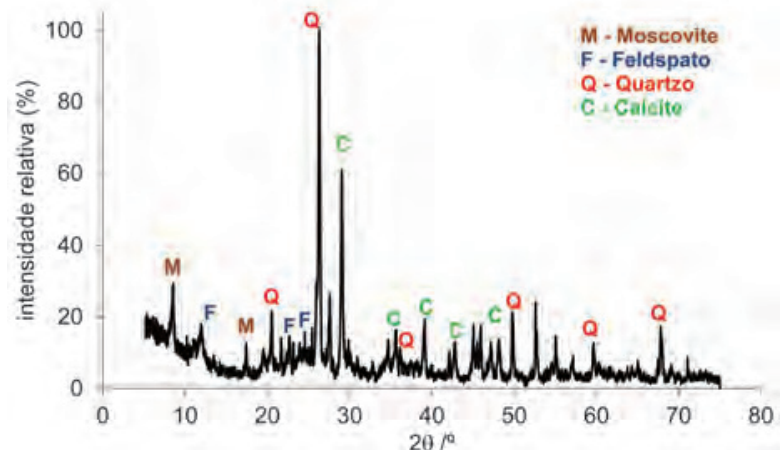

Figura 2 - Difractograma de raios-X de uma argamassa de cal, com a identificação dos picos relativos aos principais componentes. Adaptado com permissão de J. Chem. Educ. 2015, 92, 521-523. (Copyright 2015 American Chemical Society)

raios-X para as principais substâncias encontradas. Este material pode ser acedido via Internet em http://www.spq.pt.

\section{AGRADECIMENTOS}

Agradeço ao Editor do QUíMICA o convite para a escrita deste artigo, bem como ao DQB-FCUL pela oportunidade de realizar trabalhos do tipo dos que aqui foram descritos.

\section{REFERÊNCIAS}

[1] J. Mullich, "Rising to the Challenge - America's Math and Science Curriculum Is Key to Future Competitiveness", The Wall Street Journal 18 de Maio (2009)

[2] J. Vasagar, "Royal Society Calls for A-Level Overhaul to Tackle Decline in Science Students", The Guardian, 15 de Fevereiro (2011)

[3] T. Lyons, F. Quinn, Choosing Science: Understanding the Declines in Senior High School Science Enrolments. University of New England, 2010

[4] E.A. Varella, Conservation Science for the Cultural Heritage - Applications of Instrumental Analysis. Springer, Heidelberg, 2013

[5] (a) M.V. Orna, J. Chem. Ed. 57 (1980) 267-269; (b) F.W. Billmeyer, R. Kumar, M. Saltzman, J. Chem. Ed. 58 (1981) 307-313; (c) I.S. Butler, R.J. Furbacher, J. Chem. Ed. 62 (1985) 334-336; (d) M. Ware, J. Chem. Ed. 85 (2008) 612; (e) S.D. Solomon, S.A. Rutkowsky, M.L. Mahon, E. M. Halpern, J. Chem. Ed. 88 (2011) 1694-1697; (f) I.M.V. Leitão, J.S.S. de Melo, J. Chem. Ed. 90 (2013) 1493-1497; (g) T. Ferreira, R. Cristovão, A.E. Candeias, Química (Boletim da SPQ) 90 (2003) 61-64

[6] T.D. Price, J. H. Burton, An Introduction to Archaeological Chemistry, Springer, 2011

[7] F. Casadio, G. Chiari, S. Simon, Archaeometry 47 (2005) 671-89

[8] J. Miranda, A.P. Carvalho, J. Pires, Archaeometry 54 (2012) 267-277 


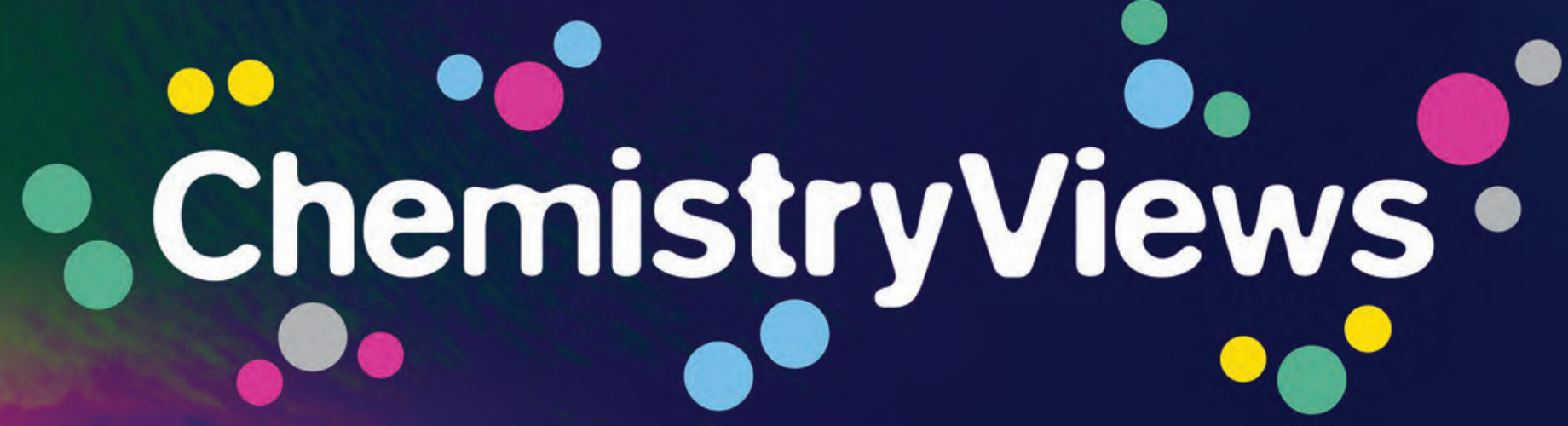

Presents top quality information from

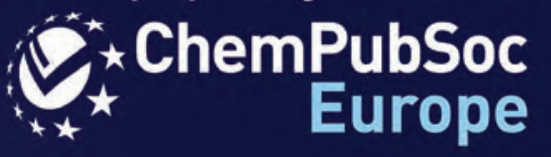

an organization of 14 chemical societies in continental Europe, publishing world leading journals like Chemistry - A European Journal

Gateway to WILEY's unique chemistry program including Angewandte Chemie, the flagship journal of

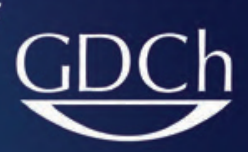

GeselLschaft Deutscher Chemiker

Free to view magazine

110:8: : Chem

\section{Spot your favorite content at}

\section{www.ChemistryViews.org}

